\title{
Gatekeeping hormone replacement therapy for transgender patients is dehumanising
}

\author{
Florence Ashley ${ }^{\circ}$
}

\section{Correspondence to}

Florence Ashley, Faculty of Law, McGill University, Montréal H3A 1W9, Canada;

florence.pare@mail.mcgill.ca

Received 4 December 2018 Revised 26 January 2019

Accepted 4 February 2019

Published Online First

15 April 2019

\begin{abstract}
Although informed consent models for prescribing hormone replacement therapy are becoming increasingly prevalent, many physicians continue to require an assessment and referral letter from a mental health professional prior to prescription. Drawing on personal and communal experience, the author argues that assessment and referral requirements are dehumanising and unethical, foregrounding the ways in which these requirements evidence a mistrust of trans people, suppress the diversity of their experiences and sustain an unjustified double standard in contrast to other forms of clinical care. Physicians should abandon this unethical requirement in favour of an informed consent approach to transgender care.
\end{abstract}

\section{INTRODUCTION}

When I decided that I wanted to take hormones to feminise my body, the last thing I wanted to do was to go in front of a psychologist to justify my decision. Deciding to take hormones was not a decision I made in haste. Moreover, like many others, I had socially transitioned months before pursuing hormone replacement therapy (HRT). Thankfully, my educational privileges provided protection: I did not have to see a psychologist for a letter of referral to get a HRT prescription because the university health clinic practised the informed consent model, which is becoming increasingly common across the USA. ${ }^{1}$ I was able to see a physician who would prescribe me oestrogen and antiandrogens without such a letter, although it is typically required under the Word Professional Association for Transgender Health (WPATH) Standards of Care (Coleman et al, p180). ${ }^{2}$ Many others are not so lucky — and my own luck ran out when I had to seek two referral letters for genital surgery.

The assessment of gender dysphoria left me feeling exposed, naked and dehumanised. Although the assessment process is alone a difficult experience, it is only made worse by the apparent conflation of gender dysphoria under the WPATH Standards of Care and Gender Dysphoria as a psychiatric diagnosis defined in the Diagnostic and Statistical Manual of Mental Disorders, Fifth Edition (DSM-5). ${ }^{3}$

Discussions of the ethics of referral requirements for HRT have tended to emphasise traditional approaches to bioethics, with arguments against those requirements primarily relying on autonomy and beneficence. ${ }^{4}$ Though ethically sound, those approaches fail to foreground the lived experiences of the trans people who undergo these assessments. I hope that my contribution, which will draw on my personal and communal experiences to illuminate the dehumanising nature of HRT gatekeeping, will motivate physicians to provide HRT on an informed consent model for older teenagers and adults. ${ }^{6}$

The informed consent model shifts focus away from the assessment of gender dysphoria and the provision of mental healthcare and instead sees the obtention of appropriate informed consent as the primary role of hormone providers (Coleman et al, p188). ${ }^{2}$ Providers working under the informed consent model typically record consent on a document listing the potential benefits, risks and limitations of HRT. Working under the informed consent model includes discussions of the patient's expectations, decision-making process, understanding of risks and benefits, support structures and general health, but does not involve an evaluation of their gender or whether they are truly trans (Chang, Singh and dickey, p143). ${ }^{7}$ The goal is not to assess but to facilitate thoughtful decision-making. The model ensures that the decision was not made in haste without appropriate knowledge and forethought, while preserving patients' own authority over their experiences and avoiding the dehumanising process criticised in the present article.

\section{MISTRUSTING TRANS VOICES}

We generally trust what other people say about their own mental states. If someone says, 'my arm hurts', we typically grant credence to their claim. We have this trust in people's self-reports of their mental states because we hold mental states to be within the purview of people's epistemic authority-authority over knowledge. ${ }^{8}$ This authority is defeasible: I do not need to demonstrate the authoritativeness of my assertion and probing questions would typically be unjustified, but if a serious reason to doubt it is present, it would be legitimate to doubt the claim and ask further questions (Bettcher and Shrage, p100). ${ }^{9}$ If someone says that their arm hurts but are laughing at the same time, we may have a good reason to doubt, yet in the absence of such conflicting indication, it would be illegitimate to doubt them. Defeasibility addresses the epistemic tension between our privileged access to our own mental states and the fallibility of that self-knowledge. ${ }^{10}$ If I were to doubt that person's claim without serious reasons to believe otherwise, I would be committing an injustice because I would unjustly fail to recognise their authoritative knowledge of their own experience of the world. ${ }^{11}$

Not all knowledge relating to mental states can be authoritatively reported by individuals. We do not typically grant credence to mental health self-diagnoses, especially not by non-professionals-though perhaps we should more often. 
However, it is important to note that self-reports of gender dysphoria do not fall within this type of specialised knowledge about mental health which is reserved for professionals. As WPATH defines it, gender dysphoria refers to 'discomfort or distress that is caused by a discrepancy between a person's gender identity and that person's sex assigned at birth (and the associated gender role and/or primary and secondary sex characteristics)' (Coleman et al, p166). ${ }^{2}$ The assessment of gender dysphoria is not an assessment of a mental health conditionthe WPATH Standards of Care predates the DSM-5 Gender Dysphoria diagnosis by a few years.

Experiences of gender dysphoria are part of the mental experiences over which we have epistemic authority. The simple report of having gender dysphoria to a physician, combined with an informed consent process to ensure that expectations match the actual effects of HRT, should suffice to obtain a prescription since gender dysphoria is distress or discomfort towards those very features that people seeking HRT want to change. By requiring that trans people submit to an assessment of gender dysphoria instead of satisfying themselves with the patient's affirmations, physicians deny the authority trans people have over their own mental experiences, an authority that should be granted to everyone by virtue of being persons. To unjustifiably deny that authority is dehumanising. Referral requirements for HRT treat self-reports of gender dysphoria not as one would treat reports of normal mental experiences, but as one would treat reports of mental illnesses. The referral requirements may reflect a failure of clinical guidelines to keep up with our evolving understanding of transitude-the fact of being transas a part of normal human diversity. As being transgender is not a mental illness, treating gender dysphoria in this way is pathologising and, because it pathologises normal human variance, dehumanising.

\section{SUPPRESSING THE DIVERSITY OF TRANS EMBODIMENT}

Medically transitioning is not all about gender dysphoria. Apart from gender dysphoria, at least two other experiences lead people to seek out HRT. Those experiences are gender euphoria and creative transfiguration.

As Ashley and Ells have explained, gender euphoria is the positive homologue of gender dysphoria', and 'speaks to a distinct enjoyment or satisfaction caused by the correspondence between the person's gender identity and gendered features associated with a gender other than the one assigned at birth'. ${ }^{12}$ For instance, instead of being distressed by my masculine fat distribution, I might simply be overjoyed by the thought of having a feminine fat distribution. Although dysphoria and euphoria typically go hand in hand, it is not always the case, and focusing solely on dysphoria would miss an essential component of why some trans people want to alter their bodies.

Creative transfiguration is more difficult to capture in words. Foregrounding creativity and aspirational aesthetics, creative transfiguration sees the body as a gendered art piece that can be made ours through transition-related interventions. It can be glimpsed in Horncastle's description of their double mastectomy as having brought them 'a sense of being able to feel a way into the poetry of (their) gender'. ${ }^{13}$ Visions of trans embodiment as a free-form artistic expression of gender can increasingly be found in the written word. ${ }^{14} 15$

People whose transition desires cannot be fully captured without accounting for gender euphoria and creative transfiguration do not have a place in the gatekeeping model which requires an assessment of gender dysphoria as a prerequisite for
HRT. Although I am not aware of any clear explanation as to why gender dysphoria would be sufficient for HRT prescriptions but not gender euphoria and creative transfiguration, I suspect that any explanation would have to appeal to an illness framework which sees gender dysphoria as a mental flaw to fix. ${ }^{12}$

Gender dysphoria assessments misrepresent trans embodiment and devalue the experiences of those who wish to alter their bodies for reasons other than gender dysphoria. Those who want to take HRT because of gender euphoria or creative transfiguration must lie about their fundamental experience of gender or be refused the gendered body they want-something cisgender people almost invariably get to have. I have myself had to sanitise my narratives of trans embodiment to access care, I have seen many others in my community report similar experiences, and instances of lying to meet clinical expectations have also been reported in the academic literature. ${ }^{14}{ }^{16}$ Both options, lying or not obtaining the desired care, are unpalatable and dehumanising. Because they don't see self-reported desire for medical transitiona as sufficient a justification to obtain a HRT prescription, mental health referral requirements fail to recognise the value of trans self-actualisation and, based on my experience with trans communities, will frequently be exepreince as dehumanising by those who do not fall under a pathologising gender dysphoria model.

Although the shift to the terminology of gender incongruence in the ICD-11 partly addresses this concern, as it is more respectful of the varied experiences of trans embodiment, requiring a gender incongruence diagnosis, which is solely available on the basis of being trans, would, unfortunately, perpetuate a pathologising odel $^{3}(\mathrm{pp} 164-165) .{ }^{17}$

\section{DOUBLE STANDARDS}

In their work on the ethics of informed consent in transgender care, Cavanaugh et al have pointed out that ' $[\mathrm{t}] \mathrm{here}$ is no scientific evidence of the benefit of (referral letter) requirements' $(\mathrm{p} 1151) .^{5}$ The requirement is based on expert consensus instead of studies linking letter requirements to positive outcomes. On the contrary, studies have shown no adverse outcomes associated with the informed consent model. ${ }^{16}$

I think their point warrants more probing. If trans bodies and lives are equally morally valuable to cis bodies—bodies belonging to cis people which have not been altered by transition-related interventions such as HRT — and lives, why should a psychological assessment be required in the absence of clear evidence of an important and overriding risk? Within a framework that sees trans people as mentally ill, the risk of misdiagnosis may seem to warrant such a requirement. But if we agree that being trans is not pathological and that trans people's desire for HRT is simply part of normal human variance, can clear evidence of such a risk be established? I do not think so. For those who, like me, do not believe that such a risk is clearly evidenced, the maintenance of assessment requirements for HRT expresses a dehumanising devaluation of trans lives and bodies.

What counts as clear evidence of an important and overriding risk is debatable, but I would argue that HRT poses no more risk than various other medical interventions for which no psychological assessment is required. We do not typically think that it is ethical to require psychological assessments prior to abortions, for instance, an intervention which bears some parallels to transition-related care. Both are frequently justified by reference to personal autonomy and are frequently but not always motivated by distress, and yet neither pregnancy nor being trans is illness. I invite physicians to answer this question for themselves and 


\section{Viewpoint}

inquire into how double standards in clinical practices may reflect an unconscious hostility towards trans lives and experiences.

\section{CONCLUSION}

Physicians are slowly but surely moving towards providing HRT on an informed consent basis, without requiring psychological assessments. I hope that this article, informed by my personal and communal experiences as a trans scholar, will shed light on the ethics of requiring an assessment of gender dysphoria by a mental health professional prior to prescribing HRT. More than just unjustified, these requirements are dehumanising and pathologising for trans people and should be abandoned.

Acknowledgements The author would like to thank Carolyn Ells for her thoughtful comments on an early version of this article.

Contributors FA is the sole contributor.

Funding This research received no specific grant from any funding agency in the public, commercial or not-for-profit sectors.

Competing interests None declared.

Patient consent for publication Not required.

Provenance and peer review Not commissioned; externally peer reviewed.

\section{REFERENCES}

1 Deutsch MB. Use of the informed consent model in the provision of cross-sex hormone therapy: a survey of the practices of selected clinics. Int I Transgend 2012;13:140-6.
2 Coleman E, Bockting W, Botzer M, et al. Standards of care for the health of transsexual, transgender, and gender-nonconforming people, version 7. Int J Transgend 2012;13:165-232.

3 Davy Z, Toze M. What is gender dysphoria? a critical systematic narrative review. Transgend Health 2018;3:159-69.

4 Hale CJ. Ethical problems with the mental health evaluation standards of care for adult gender variant prospective patients. Perspect Biol Med 2007:50:491-505.

5 Cavanaugh T, Hopwood R, Lambert C. Informed consent in the medical care of transgender and gender-nonconforming patients. AMA J Ethics 2016;18:1147-55.

6 Blasdel G, Belkind U, Harris A, et al. Description and outcomes of a hormone therapy informed consent model for minors. Buenos Aires, Argentina: Poster presented at the: 25th WPATH Symposium, 2018.

7 Chang SC, Singh AA, Dickey LM. A Clinician's Guide to Gender-Affirming Care: Working with Transgender \& Gender-Nonconforming Clients. Oakland, California: Context Press, 2018.

8 Parrott M, Authority EF-PPhilos Stud 2015;172:2215-37.

9 Bettcher TM, Shrage L. Trans identities and first-person authority. You've changed: sex reassignment and personal identity. Oxford: Oxford University Press, 2009:98-120.

10 Mccullagh M. Self-Knowledge Failures and First Person Authority ${ }^{1}$. Philos Phenomenol Res 2002;64:365-80.

11 In: Kidd IJ, Medina J, Pohlhaus G, eds. The routledge handbook of epistemic injustice. New York: Routledge, 2017.

12 Ashley F, Ells C. In favor of covering ethically important cosmetic surgeries: facial feminization surgery for transgender people. The American Journal of Bioethics 2018;18:23-5.

13 Horncastle J. Busting Out. TSQ: Transgender Studies Quarterly 2018;5:251-67.

14 Spade D, Gender M. In: Stryker S, Whittle S, The transgender studies reader. Hoboken: Taylor and Francis, 2013:315-32.

15 Preciado PB. Testo junkie: sex, drugs, and biopolitics in the pharmacopornographic era. New York, NY: The Feminist Press at the City University of New York, 2013.

16 Pimenoff $\mathrm{V}$, Pfäfflin F. Transsexualism: treatment outcome of compliant and noncompliant patients. Int J Transgend 2011;13:37-44.

17 World Health Organisation. The ICD-11 Classification of Mental and Behavioural Disorders: Clinical Descriptions and Diagnostic Guidelines. Geneva: World Health Organisation, 2018 